\title{
A Kinetic Method for the Determination of Carbimazole in Pharmaceutical Preparations by Oxidation with Dichromate in Sulfuric Acid
}

\author{
Salah M. Sultan \\ Chemistry Department, College of Science, King Fahd University for Petroleum and Minerals, \\ Kfupm Box 2026, Dhahran 31261, Saudi Arabia
}

\begin{abstract}
A simple spectrophotometric method is introduced for the determination of carbimazole in drug formulation. The method requires the use of $16 \mathrm{mg} \mathrm{ml}^{-1}$ potassium dichromate, $0.5 \mathrm{M}$ sulfuric acid and heating at $90^{\circ} \mathrm{C}$ for $25 \mathrm{~min}$. The method is easily applied to the determination of carbimazole in tablet formulations. The accuracy of the method was tested by a statistical comparison with the British Pharmacopeia official method.
\end{abstract}

Keywords Carbimazole, potassium dichromate, fixed time method, kinetics, spectrophotometry

Carbimazole is a carboethoxy derivatives of methimazole. ${ }^{1}$ Chemically it is ethyl 3-methyl-2-thioxo-4imidazoline-1-carboxylate. It is used for the treatment of hypothyroidism or thyrothexicosis which occurs in goithers. It reduces the uptake and concentration of inorganic iodine by the thyroid gland, but its main effect is to reduce the formation of diiodothyrosine and hence of thyroxine. ${ }^{2}$ It is known to be readily hydrolyzed in acid and alkaline media and thus easily converted to methimazole in the presence of plasma..$^{3-5}$ It is believed to owe its antithyroid activity to the formation of methimazole in vivo. In seeking to establish quantitative methods for the determination of carbimazole, investigators have focused attention on methods for the detection and determination of methimazole. Methods for the determination of carbimazole and methimazole ${ }^{6-17}$ include titrimetry ${ }^{6-8}$, chromatography ${ }^{4}$, electrochemical procedures ${ }^{11,12}$ and spectrophotometry. ${ }^{13,14}$ The British Pharmacopeia ${ }^{14}$ described a spectrophotometric method for the determination of carbimazole by measuring the absorbance of the aqueous solution at $291 \mathrm{~nm}$.

The objective of this work is to develop a specific method for the determination of carbimazole to substitute for the unspecific British Pharmacopeia ${ }^{14}$ method using potassium dichromate as an oxidant in sulfuric acid media. The concentration of carbimazole is calculated from the absorbance of chromium(III) at $585 \mathrm{~nm}$ at the fixed time of $25 \mathrm{~min}$ after heating at $90^{\circ} \mathrm{C}$.

\section{Experimental}

\section{Reagents and samples}

Stock solutions were prepared from analytical or pharmaceutical grade chemicals and high purity distilled water. Working solutions were prepared by appropriate dilutions of the stock solutions.

Potassium dichromate solution $\left(80 \mathrm{mg} \mathrm{ml}^{-1}\right)$ was prepared in $2.5 \mathrm{M}$ sulfuric acid.

Carbimazole reference standard $\left(1 \mathrm{mg} \mathrm{m}^{-1}\right)$ was prepared from a pure analytical sample of Batch No. 03604 and supplied by Nicholas Lab. Ltd. This was prepared by dissolving exactly about $0.500 \mathrm{~g}$ in about $200 \mathrm{ml}$ warm water, the mixture was stirred for $10 \mathrm{~min}$ and diluted to volume in a $500 \mathrm{ml}$ calibrated flask after cooling.

Carbimazole solution $\left(1 \mathrm{mg} \mathrm{ml}^{-1}\right): 30$ tablets of the proprietary product, Neomercazole, were accurately weighed and powdered. An amount equivalent to $0.100 \mathrm{~g}$ of carbimazole was dissolved in about $30 \mathrm{ml}$ of chloroform, warmed and stirred for $10 \mathrm{~min}$, then filtered through a Whatman No. 41 filter paper and washed with warm chloroform. The combined filtrate and washings were evaporated to dryness and the residue was dissolved in about $50 \mathrm{ml}$ warm water, the mixture was stirred for $10 \mathrm{~min}$, cooled to room temperature and finally made up to volume in a $100 \mathrm{ml}$ calibrated flask.

\section{Apparatus}

A Cary Model 2300 UV-V-NIR spectrophotometer connected to a Varian DS-15 Data station and Epson LX-86 printer, was used for all absorbance measurements. Matched sets of W210/UU $10.00 \mathrm{~mm}$ path length cells were used throughout.

\section{Recommended procedure}

In a 50-ml calibrated flask, place $10 \mathrm{ml}$ of the potassium dichromate stock solution, add the appropriate amount of carbimazole stock solution and dilute to 
the mark with distilled water, so that a final concentration of carbimazole is in the range $40-300 \mu \mathrm{g}$ $\mathrm{ml}^{-1}$. Swirl the flask with its contents, turn the stopwatch on and immediately put the flask in a water bath thermostated at $90^{\circ} \mathrm{C}$. At a fixed time of $25 \mathrm{~min}$ directly measure the absorbance of the green color of chromium(III) species at $\lambda_{\max } 585 \mathrm{~nm}$ against a reagent blank treated similarly. Calculate the amount of carbamizole from the calibration graph.

\section{Results and Discussion}

\section{Reaction kinetics and optimization}

This method is based on the oxidation of carbimazole with potassium dichromate. The reaction rate could be monitored by the increase in absorbance of the resultant chromium(III) species at $\lambda_{\max } 585 \mathrm{~nm}$ at a preselected fixed-time for the kinetic determination of carbimazole. At this wavelength, the oxidized form of the carbimazole does not absorb. The reaction is strongly dependent on reaction conditions and proceeds slowly to final products over several hours. The rate increases with increasing temperature and concentrations of carbimazole, potassium dichromate and sulfuric acid. The dependence of the reaction rate on carbimazole concentration is illustrated in Fig. 1 which clearly shows an increase in rate as carbimazole concentration is increased. As the fixed-time method requires conducting the reaction in an

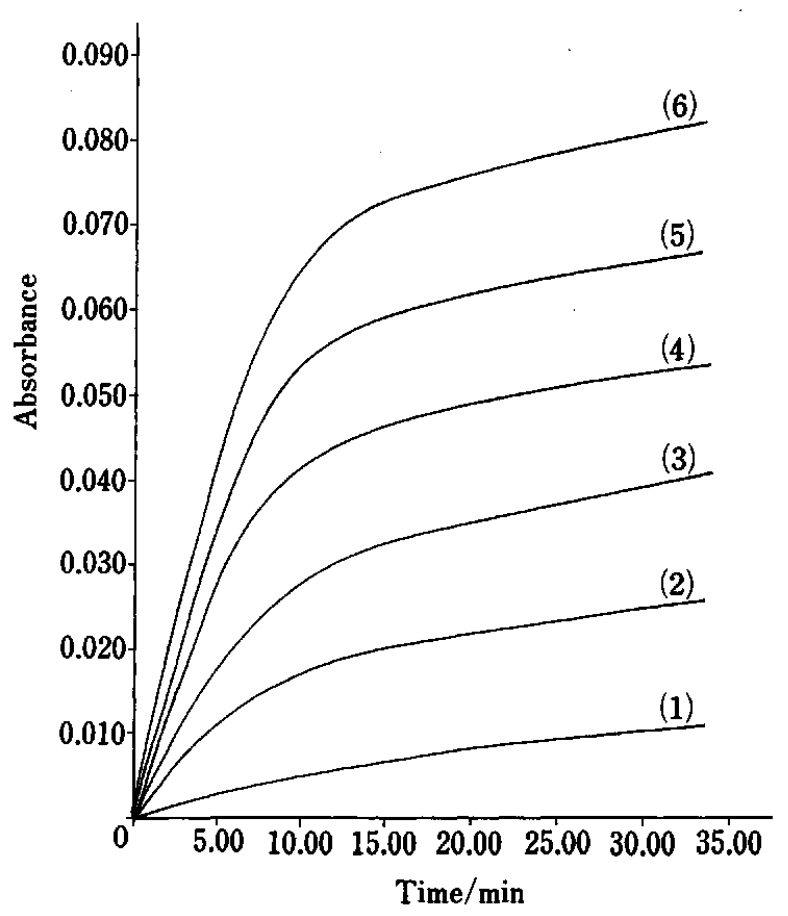

Fig. 1 Absorbance-time graphs for the reaction between carbimazole and potassium dichromate taking constant concentrations of $0.5 \mathrm{M}$ sulfuric acid and $16 \mathrm{mg} \mathrm{ml}^{-1}$ potassium dichromate and at different initial concentrations of carbimazole of (1) 40 ; (2) 100 ; (3) 150 ; (4) 200 ; (5) 250 ; (6) $300 \mu \mathrm{g} \mathrm{ml}^{-1}$. excess of the oxidant, the highest concentration of potassium dichromate was limited to $16 \mathrm{mg} \mathrm{ml}^{-1}$, above which the rate did not change significantly. Increasing the sulfuric acid concentration increased the absorbance significantly up to $0.5 \mathrm{M}$ and had little effect above this concentration. Therefore the reaction was conducted in $0.5 \mathrm{M}$ sulfuric acid. The reaction rate was also found to increase with temperature. Working above $90^{\circ} \mathrm{C}$ is not recommended, to avoid chemical decomposition of carbimazole. Under the recommended conditions, the reaction is slow, after $25 \mathrm{~min}$. The rate of change of absorbance is 0.0001 absorbance units per $5 \mathrm{~min}$, so there is time enough for transference from water bath and measurements without significant errors in readings. It is therefore, not necessary to stop the reaction by any technique ${ }^{16}$ such as cooling or changing $\mathrm{pH}$.

\section{The fixed time method}

Under the above conditions, carbimazole is always in a very low concentration compared to the concentrations of the dichromate and sulfuric acid; hence, the reaction rate is dependent upon the change in the initial concentration carbimazole and follows the following pseudo-first-order rate equation:

$$
\text { Rate }=\Delta A / \Delta t=k^{\prime}[\text { carbimazole }]_{0} .
$$

The overall redox reaction is:

$$
\mathrm{Cr}_{2} \mathrm{O}_{7}^{2-}+6 \mathrm{RSH}+8 \mathrm{H}^{+} \longrightarrow 3 \mathrm{RSSR}+2 \mathrm{Cr}^{3+}+7 \mathrm{H}_{2} \mathrm{O}
$$

where RSH is the protonated reactant substrate i.e. carbimazole, and RSSR is the substrate in the diameric form.

The above reaction can be simplified to:

$$
3 \mathrm{RSH} \longrightarrow \mathrm{Cr}^{3+} \text {. }
$$

Then the pseudo-first-order equations are:

$$
\text { Rate }=-\mathrm{d}[\mathrm{RSH}] / \mathrm{d} t=1 / 3\left[\mathrm{Cr}^{3+}\right] / \mathrm{d} t=k[\mathrm{RSH}] .
$$

If reaction is carried on over a fixed time interval 0 to $t$ min, for known standard concentrations and unknown sample concentration $x$, the integrated rate equations are:

$$
\begin{aligned}
& {\left[\mathrm{Cr}^{3+}\right]_{\mathrm{x}}=3[\mathrm{RSH}]_{\mathrm{ox}}\left(1-\mathrm{e}^{-k t}\right)} \\
& {\left[\mathrm{Cr}^{3+}\right]_{\mathrm{s}}=3[\mathrm{RSH}]_{\mathrm{os}}\left(1-\mathrm{e}^{-k t}\right)}
\end{aligned}
$$

Take the ratios of these equations, and transform:

$$
\frac{[\mathrm{RSH}]_{0, \mathrm{x}}}{[\mathrm{RSH}]_{0, \mathrm{~s}}}=\frac{\left[\mathrm{Cr}^{3+}\right]_{\mathrm{x}}}{\left[\mathrm{Cr}^{3+}\right]_{\mathrm{s}}}=\frac{\left(\mathrm{Cr}^{3+} \text { absorbance }\right)_{\mathrm{x}}}{\left(\mathrm{Cr}^{3+} \text { absorbance }\right)_{\mathrm{s}}}
$$

where subscript s designates standard concentration, 


$$
[\mathrm{RSH}]_{0, \mathrm{x}}=[\mathrm{RSH}]_{\mathrm{o}, \mathrm{s}} \frac{\left(\mathrm{Cr}^{3+} \text { absorbance }\right)_{\mathrm{x}}}{\left(\mathrm{Cr}^{3+} \text { absorbance }\right)_{\mathrm{s}}} .
$$

Finally:

$$
[\mathrm{RSH}]_{\mathrm{x}}=\text { constant }\left(\mathrm{Cr}^{3+} \text { absorbance }\right)_{\mathrm{x}} .
$$

Hence, the observed absorbance of the unknown sample after fixed reaction time $t$ is proportional to the original concentration.

The fixed time method was found to be the one suitable for the determination of carbimazole. Rates of the reaction were measured under constant concentrations of $16 \mathrm{mg} \mathrm{ml}^{-1}$ potassium dichromate and $0.5 \mathrm{M}$ sulfuric acid and heating at $90^{\circ} \mathrm{C}$ for different initial concentrations of carbimazole in the range $40-300 \mu \mathrm{g} \mathrm{ml}^{-1}$ (see a typical graph in Fig. 1). A computer regression of absorbance, measured at fixed times of $10,15,20,25$ and 30 min versus initial carbimazole concentrations, gave straight lines with the calibration equations shown in Table 1. All calibration equations are acceptable and favorable and $25 \mathrm{~min}$ was chosen as the fixed time (a calibration graph is shown in Fig. 2). Table 1 shows that slopes and intercepts increase with time, indicating higher

Table 1 Calibration equations obtained by the fixed-time method for the determination of carbimazole in the range $40-300 \mu \mathrm{g}^{-1}$ at different times with constant concentrations of $16 \mathrm{mg} \mathrm{ml}^{-1}$ potassium dichromate, $0.5 \mathrm{M}$ sulfuric acid and heating at $90^{\circ} \mathrm{C}$ for $25 \mathrm{~min}$

\begin{tabular}{ccc}
\hline Time $/ \mathrm{min}$ & Calibration equation & $\begin{array}{c}\text { Correlation } \\
\text { coefficient }\end{array}$ \\
\hline 10 & $A=-0.00578+0.000234 C$ & 0.993 \\
15 & $A=-0.00460+0.000254 C$ & 0.996 \\
20 & $A=-0.00352+0.000260 C$ & 0.998 \\
25 & $A=-0.00250+0.000264 C$ & 0.999 \\
30 & $A=-0.00154+0.000269 C$ & 0.999 \\
\hline
\end{tabular}

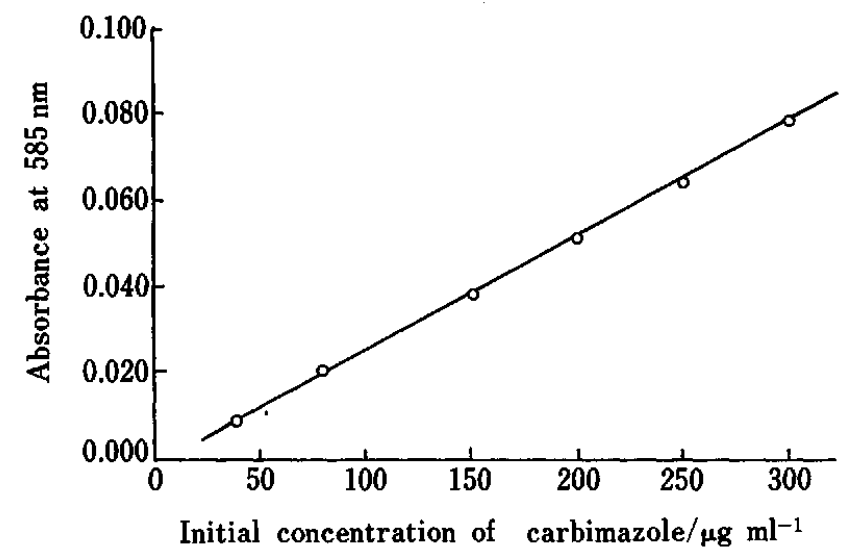

Fig. 2 A calibration curve for absorbance versus initial carbimazole concentrations in the range $40-300 \mu \mathrm{g} \mathrm{ml}^{-1}$ obtained by the potassium dichromate method with $25 \mathrm{~min}$ reaction time. sensitivities. The plots of absorbance versus original substrate concentration, at various reaction times, were not always straight lines, but showed distinct curvature at the lower concentrations for the lower times. The systematically increasing regression slopes and the negative regression intercepts are consequences of misfitting straight lines to graphs that have curvature on the left. At concentrations, of carbimazole less than $40 \mu \mathrm{g} \mathrm{ml}^{-1}$ the method showed poor sensitivity. Above $300 \mathrm{~g} \mathrm{ml}^{-1}$, the rate of the reaction becomes too fast and absorbance measurements are not favorable due to the difficulty in taking readings.

\section{Proposed mechanism}

The oxidation of carbimazole with sodium dichromate is suggested to proceed to the disulfide compound through the formation of methimazole $4,5,10$ according to the following scheme:<smiles>CCOC(=O)n1ccn(C)c1=S</smiles><smiles>CN1C=CNC1</smiles><smiles></smiles>

Figure 1 implies that the reaction rate slows down at later times and absorbance increases slowly. This could be due to the fact that the initial reduction of $\mathrm{Cr}_{2} \mathrm{O}_{7}{ }^{2-}$ to $\mathrm{Cr}\left(\mathrm{H}_{2} \mathrm{O}\right)_{6}{ }^{3+}$ is followed by a shorter conversion of the $\mathrm{Cr}\left(\mathrm{H}_{2} \mathrm{O}\right)_{6}{ }^{3+}$ to a $\mathrm{Cr}\left(\mathrm{H}_{2} \mathrm{O}\right)_{x}\left(\mathrm{H}_{2} \mathrm{SO}_{4}\right)_{y}$ species of similar but of higher absorbance.

\section{Application of the method}

For the purpose of studying the applicability of the method being used in quality control of the drug in proprietary preparations, the method is applied to Neomercazole tablets (Neo-Mercazole tablet is the only drug containing carbimazole active ingredient in the area). The same batch of Neo-Mercazole tablets were analyzed for carbimazole using the British Pharmacopeia method. ${ }^{14}$ The results obtained by using both methods are found in Table 2 with the student-t-test values indicated in the last column of the table as a statistical comparison between the two methods. This comparison is made for low concentrations of carbimazole in the range $40-70 \mu \mathrm{g} \mathrm{ml}^{-1}$, since the British Pharmacopeia method is not applicable for higher than $70 \mu \mathrm{g} \mathrm{ml}^{-1}$. The results indicate that this method is as accurate as the British Pharmacopeia method. Also it is indicating that excipients added for making the tablets, such as glucose, starch have no effect on the determination. The dichromate method has the advantage of being applicable in a wider working range of carbimazole concentration and considered to be more specific than British 
Table 2 Results of determination of carbimazole ( 5 replicates) in Neo-Mercazole ${ }^{a}$ proprietary drug by this method, compared with those obtained by the BP method

\begin{tabular}{|c|c|c|c|c|c|c|c|}
\hline \multirow{2}{*}{$\begin{array}{l}\text { Carbimazole } \\
\text { taken } / \mu \mathrm{g} \mathrm{ml}^{-1}\end{array}$} & \multicolumn{3}{|c|}{ Dichromate method } & \multicolumn{3}{|c|}{ BP method } & \multirow{2}{*}{$t^{b}$} \\
\hline & Found $/ \mu \mathrm{g} \mathrm{ml}^{-1}$ & Relative error, $\%$ & SD & Found $/ \mu \mathrm{g} \mathrm{ml}^{-1}$ & Relative error,\% & SD & \\
\hline 10 & & & & 10.1 & 0.6 & 0.0 & - \\
\hline 20 & & & & 20.0 & -0.1 & 0.9 & - \\
\hline 30 & & & & 29.8 & 0.7 & 0.3 & - \\
\hline 40 & 39.7 & -0.7 & 0.2 & 39.6 & -0.9 & 0.4 & 2.2 \\
\hline 50 & 49.7 & -0.6 & 0.6 & 49.4 & -1.1 & 0.3 & 1.8 \\
\hline 60 & 60.1 & 0.1 & 0.7 & 59.8 & -0.4 & 0.2 & 1.6 \\
\hline 70 & 70.2 & 0.3 & 0.4 & 70.3 & 0.4 & 0.6 & 0.6 \\
\hline \multicolumn{2}{|c|}{ Average absolute error $\%$} & 0.7 & & & 0.6 & & \\
\hline
\end{tabular}

a. Neo-mercazole is commercially available in tablet form, a product of Nicholas Lab. Ltd., and each tablet is claimed to contain $5 \mathrm{mg}$. b. Theoretical value calculated for the student-t-test $=2.78(P=0.05)$.

Pharmacopeia method.

\section{Comparison of the method with the British Pharmacopeia method}

The present kinetic method is superior than the British Pharmacopeia method ${ }^{14}$ with respect to specificity. The reaction proceeds under certain conditions, rendering the organic excipients usually added in drug formulations unrective, and does not create interference problems under the reaction conditions as heating, acid concentration and fixed time.

Thanks is due to Nicholas Lab. Ltd., for supplying the carbimazole standard.

\section{References}

1. A. G. Gilman, L. S. Goodman and A. Gilman, "The Pharmacological Basis of Therapeutics", 6th ed., p. 1397, Machmillan, New York, 1980.

2. Martindale, 28th ed., Reynolds, The Pharm. Press, London, 1982.

3. A. Taurog, Endocrinology, 98, 1031 (1976).

4. J. B. Stenlake, W. D. Williams and, G. G. Skellern, $J$. Chromatogr., 53, 285 (1970).

5. B. Morchant, W. D. Alexander and J. H. Lazarus, J. Clin.
Endocrinol., 34, 847 (1972).

6. E. Varga and E. Zollner, Acta Pharm. Hung., 25, 150 (1955).

7. E. Zollner and E. Varga, Acta Chem. Acad. Sci. Hung., 12, 1 (1957).

8. G. Posgay, Pharm. Zentralhalle, 100, 6572 (1961).

9. I. Bayer and G. Posgay, Acta Pharm. Hung., 31, 43 (1961).

10. K. Sriraman, N. R. Sastry, B. V. S. Sastry and G. N. L. Prasuna, Indian Drugs, 21(II), 520 (1984).

11. S. Pinzauti, V. Dal Piaz and E. La Porta, Farmaco. Ed. Prat., 28 (7), 396 (1973).

12. C. A. Mairesse, J. L. Vandenback and G. J. Patriarche, J.Pharm. Belg., 28, 300 (1973).

13. A. Bult and H. B. Klasen, Pharm. Weekbl. Ned., 109 (17), 389 (1974).

14. "British Pharmacopeia", p. 80, HM Stationary Office, London, 1980.

15. D. Perez-Bendito and M. Silva, "Kinetic Methods in Analytical Chemistry", p. 47, Ellis Horwood, Chichester, 1988.

16. A. Weisberger, S. L. Freiss and E. S. Lewis, "Techniques of Organic Chemistry", Vol. III, p. 109, Interscience, New York, 1953.

17. H. Y. Aoul-Enein, A. A. Al-Badr, "Analytical Profiles of Drug Substances”, Vol. 8, p. 351, 1979.

(Received February 28, 1992) (Accepted June 1, 1992) 